\title{
Phenotyping diabetic cardiomyopathy in Europeans and South Asians
}

\author{
Elisabeth H. M. Paiman 1* (D, Huub J. van Eyk², Maurice B. Bizino², Ilona A. Dekkers', Paul de Heer',
} Johannes W. A. Smit ${ }^{3}$, Ingrid M. Jazet ${ }^{2}$ and Hildo J. Lamb

\begin{abstract}
Background: The pathogenesis and cardiovascular impact of type 2 diabetes (T2D) may be different in South Asians compared with other ethnic groups. The phenotypic characterization of diabetic cardiomyopathy remains debated and little is known regarding differences in T2D-related cardiovascular remodeling across ethnicities. We aimed to characterize the differences in left ventricular (LV) diastolic and systolic function, LV structure, myocardial tissue characteristics and aortic stiffness between T2D patients and controls and to assess the differences in T2D-related cardiovascular remodeling between South Asians and Europeans.
\end{abstract}

Methods: T2D patients and controls of South Asian and European descent underwent 3 Tesla cardiovascular magnetic resonance imaging (CMR) and cardiac proton-magnetic resonance spectroscopy ( $\left.{ }^{1} \mathrm{H}-\mathrm{MRS}\right)$. Differences in cardiovascular parameters between T2D patients and controls were examined using ANCOVA and were reported as mean $(95 \% \mathrm{Cl})$. Ethnic group comparisons in the association of T2D with cardiovascular remodeling were made by adding the interaction term between ethnicity and diabetes status to the model.

Results: A total of 131 individuals were included (54 South Asians [50.1 \pm 8.7 years, 33\% men, 33 patients vs. 21 controls) and 77 Europeans ( $58.8 \pm 7.0$ years, $56 \%$ men, 48 patients vs. 29 controls)]. The ratio of the transmitral early and late peak filling rate (E/A) was lower in T2D patients compared with controls, in South Asians $[-0.20(-0.36 ;-0.03)$, $P=0.021]$ and Europeans $[-0.20(-0.36 ;-0.04), P=0.017]$, whereas global longitudinal strain and aortic pulse wave velocity were similar. South Asian T2D patients had a higher LV mass [ $22 \mathrm{~g}(15 ; 30), P<0.001]$ ( $P$ for interaction by ethnicity $=0.005)$ with a lower extracellular volume fraction $[-1.9 \%(-3.4 ;-0.4), P=0.013]$ ( $P$ for interaction $=0.114)$, whilst European T2D patients had a higher myocardial triglyceride content $[+0.59 \%(0.35 ; 0.84), P=0.001]$ ( $P$ for interaction $=0.002$ ) than their control group.

Conclusions: Diabetic cardiomyopathy was characterized by impaired LV diastolic function in South Asians and Europeans. Increased LV mass was solely observed among South Asian T2D patients, whereas differences in myocardial triglyceride content between T2D patients and controls were only present in the European cohort. The diabetic cardiomyopathy phenotype may differ between subsets of T2D patients, for example across ethnicities, and tailored strategies for T2D management may be required.

Keywords: Diabetes mellitus, type 2, Diabetic cardiomyopathies, Myocardial steatosis, Myocardial diffuse fibrosis, Proton-magnetic resonance spectroscopy, T1 mapping, European, South Asian

\footnotetext{
*Correspondence: E.H.M.Paiman@lumc.nl

1 Dept. Radiology, Leiden University Medical Center, P.O. Box 9600, Postal

Zone C2-S, 2300 RC Leiden, The Netherlands

Full list of author information is available at the end of the article
} 


\section{Background}

Type 2 diabetes (T2D), independent of other cardiovascular risk factors, is associated with an increased risk of heart failure [1]. South Asians, who represent $20 \%$ of the world's population, are at particular risk of developing T2D [2,3]. Individuals of South Asian descent appear to have a metabolically disadvantageous phenotype with a relatively high total body fat percentage $[4,5]$. Also, the metabolic sensitivity to excess fat mass may be more pronounced among South Asians compared with other ethnic groups, as indicated by increased insulin resistance at similar adiposity levels $[6,7]$. In individuals of South Asian descent, the release of adipose tissue metabolites may be disturbed [8]. Also, in South Asians in particular, excess fat mass may cause a state of chronic inflammation [9]. Importantly, the impact of T2D on cardiac function may be greater among South Asians compared with Europeans [10]. However, most previous studies on diabetic cardiomyopathy were performed in white populations or ethnicity was not reported [11-13]. Little is known regarding the differences in the diabetic cardiomyopathy phenotype across ethnicities, whereas increased insight into the ethnic-specific cardiovascular consequences may guide the development of tailored strategies for the management of T2D.

By using cardiovascular magnetic resonance (CMR), the impact of T2D on the left ventricle (LV) can be characterized on a functional, structural and myocardial tissue level. Strain echocardiography studies have shown that not merely LV diastolic function, which may be most susceptible to myocardial energy depletion, but also LV systolic function might be impaired [14]. The introduction of feature tracking has enabled the assessment of both longitudinal and circumferential strain based on standard cine images, which can be considered more sensitive measures of myocardial contractility compared with LV ejection fraction [15]. Myocardial diffuse fibrosis, as the result of hyperglycemia and systemic inflammation in T2D, may be an early hallmark of LV remodeling, preceding functional impairments [16]. Also, myocardial steatosis has been proposed as an important contributing factor to both structural and functional cardiac remodeling in patients with T2D [12-14]. In this study, we aimed to characterize the differences in LV diastolic and systolic function, LV structure and myocardial tissue characteristics and aortic stiffness between T2D patients and controls and to assess the differences in T2D-related cardiovascular remodeling between South Asians and Europeans.

\section{Methods}

\section{Study population}

This is a single-center, cross-sectional study. The data of the T2D patients of European and South Asian origin (i.e. Hindustani Surinamese, Indian, Pakistani, Bangladeshi or Sri Lankan) were derived from the baseline measurements of two previous randomized controlled trials (ClinicalTrials.gov NCT01761318 [17] and NCT02660047 [18], respectively). In addition, healthy controls of European and South Asian descent in the same age range and with a similar sex distribution as compared with the T2D patients were prospectively enrolled. Ethnicity was based on self-identified origin and self-reported origin of both biological parents and their ancestors. Written informed consent was obtained prior to inclusion. The study complied with the revised Declaration of Helsinki and was approved by the institutional review board (Leiden University Medical Center, Leiden, The Netherlands).

All T2D patients were obese [body mass index $(B M I) \geq 25 \mathrm{~kg} / \mathrm{m}^{2}$ for Europeans and $\geq 23 \mathrm{~kg} / \mathrm{m}^{2}$ for South Asians] and used metformin, sulfonylurea derivatives and/or insulin. Initially, the inclusion criteria for the European and South Asian study population were similar. However, due to the insufficient number of eligible T2D patients, the inclusion criteria for the South Asians were adjusted. For the European and South Asian T2D patients, respectively, age ranged from $18-70$ and 18-75 year, glycated hemoglobin (HbA1c) was $\geq 52.5$ and $<86.5 \mathrm{mmol} / \mathrm{mol}(\geq 7.0$ and $\leq 10.0 \%)$ and $\geq 47.5$ and $<96.5 \mathrm{mmol} / \mathrm{mol}$ ( $\geq 6.5$ and $\leq 11.0 \%$ ), systolic and diastolic blood pressure was $<150 / 85 \mathrm{mmHg}$ and $<180 / 110 \mathrm{mmHg}$, estimated glomerular filtration rate (eGFR) was $>60 \mathrm{~mL} / \mathrm{min} / 1.73 \mathrm{~m}^{2}$ and $>30 \mathrm{~mL} /$ $\min / 1.73 \mathrm{~m}^{2}$, no history of significant coronary artery disease for the European T2D group (significant coronary artery disease was defined as: a history of coronary artery bypass grafting and/or percutaneous coronary intervention or significant coronary artery stenosis proven by coronary angiography or non-invasive imaging), and no acute coronary accident in the preceding 30 days for the South Asian T2D group. Main exclusion criteria were: any contra-indication for contrast-enhanced CMR and heart failure New York Heart Association class III-IV. All T2D patients were screened for abnormalities on rest echocardiography (ECG). For the present study, all T2D patients with significant coronary artery disease or valvular disease were excluded.

The healthy controls were recruited by advertisements in Leiden University Medical Center (Leiden, The Netherlands) and in local newspapers. Individuals aged 40-70 years without a history of cardiovascular disease, no medication use and no contra-indications for contrast-enhanced CMR were eligible for participation in the 
healthy control group. Exclusion criteria were: prediabetes or diabetes [fasting glucose $\geq 6.1 \mathrm{mmol} / \mathrm{L}, 2$-h glucose after $75 \mathrm{~g}$ glucose $\geq 7.8 \mathrm{mmol} / \mathrm{L}$ or $\mathrm{HbAlc} \geq 39 \mathrm{mmol} /$ $\mathrm{mol}(\geq 5.7 \%)]$, metabolic syndrome $\{\geq 2$ of the following criteria: systolic and diastolic blood pressure blood pressure $\geq 140 / 90 \mathrm{mmHg}$; triglycerides $\geq 1.7 \mathrm{mmol} / \mathrm{L}$; HDL-cholesterol $<0.9 \mathrm{mmol} / \mathrm{L}$ for men or $<1.0 \mathrm{mmol} / \mathrm{L}$ for women; obesity $\left(\mathrm{BMI} \geq 30 \mathrm{~kg} / \mathrm{m}^{2}\right)$ or abdominal obesity [waist/hip ratio: $>0.9$ for men or $>0.85$ for women or waist circumference: $\geq 102 \mathrm{~cm}$ for men or $\geq 88 \mathrm{~cm}$ for women (Europeans); $\geq 90 \mathrm{~cm}$ for men or $\geq 80 \mathrm{~cm}$ for women (South Asians)]\}, abnormalities upon physical examination, laboratory assessment (blood count, liver and kidney function) or rest ECG.

\section{Data collection}

Study participants were included after a screening visit. Clinical and CMR examinations were scheduled either in the morning or evening, after an overnight or $6 \mathrm{~h}$ fast, respectively (for T2D patients, the insulin dose was adjusted and other glucose-lowering medication was temporarily discontinued). Smoking status was selfreported and was categorized as currently vs. previously or never. Blood pressure was measured in seated position on the right arm after rest, using a validated automatic oscillometric device (SureSigns VS3, Philips, Best, The Netherlands) and was the mean of two consecutive measurements. HbA1c was examined with ion-exchange high-performance liquid chromatography (HPLC; Tosoh G8, Sysmex Nederland B.V., Etten-Leur, The Netherlands). Lipid levels were assessed on a Modular P800 analyzer (Roche Diagnostics, Mannheim, Germany) with calculation of low-density lipoprotein (LDL)-cholesterol according to the Friedewald formula. The total body fat percentage was derived from bioelectrical impedance analysis (BIA; Bodystat 1500, Bodystart Ltd., Douglas, United Kingdom).

\section{CMR acquisition and analysis}

CMR scans were acquired using a 3 Tesla MR scanner with a dStream Torso anterior coil and a FlexCoverage posterior coil, with up to 32 coil elements for signal reception (Ingenia, Philips, Best, The Netherlands).

\section{VAT and abdominal SAT}

Visceral and abdominal subcutaneous adipose tissue (VAT and abdominal SAT) were assessed on 2-point Dixon water-fat separated transverse images of the abdomen. VAT and abdominal SAT were semi-automatically measured based on pixel intensity thresholding on three reformatted transverse slices at the level of the fourth and fifth lumbar vertebrae, with slice thickness of $10 \mathrm{~mm}$ and slice gap of $12 \mathrm{~mm}$ (repetition time (TR) $3.5 \mathrm{~ms}$, first/ second echo time (TE) $1.19 / 2.3 \mathrm{~ms}$, flip angle (FA) $10^{\circ}$, field of view (FOV) $500 \times 365 \mathrm{~mm}^{2}$, acquired voxel size $1.60 \times 1.70 \mathrm{~mm}^{2}$, slice thickness $4 \mathrm{~mm}$, slice gap $-2 \mathrm{~mm}$, number of slices 140). VAT and abdominal SAT were quantified as the mean area in squared centimeters of all three slices (MASS version 2015-EXP, Leiden University Medical Center, Leiden, The Netherlands).

\section{LV systolic and diastolic function}

LV function was examined on breath-hold ECG-triggered short-axis and 2-, 3- and 4-chamber long-axis cine balanced steady-state free precession [TE/TR $1.5 / 3.0 \mathrm{~ms}$, FA $45^{\circ}$, FOV $350 \times 350 \mathrm{~mm}^{2}$ (4-chamber) and $400 \times 352 \mathrm{~mm}^{2}$ (short-axis), acquired voxel size $2.0 \times 1.6 \mathrm{~mm}^{2}$ (4-chamber) and $1.5 \times 1.5 \mathrm{~mm}^{2}$ (short-axis), slice thickness $8 \mathrm{~mm}$, number of phases 30 (4-chamber) and 35 (short-axis)] and free-breathing ECG-gated whole-heart gradientecho 4D velocity-encoded MR [venc $150 \mathrm{~cm} / \mathrm{s}$, TE/TR $4.6 / 9.0 \mathrm{~ms}$, FA $10^{\circ}$, FOV $360 \times 360 \mathrm{~mm}^{2}$, acquired voxel size $3.0 \times 3.0 \mathrm{~mm}^{2}$, slice thickness $3 \mathrm{~mm}$, number of slices 41 , number of phases 30 , sensitivity encoding (SENSE) factor 2].

LV systolic function parameters included LV ejection fraction measured on short-axis cines (MASS version 2015-EXP, Leiden University Medical Center, Leiden, The Netherlands) and global longitudinal and circumferential strain (GLS and GCS) derived from long-axis and short-axis cines using feature tracking (QStrain 2.0, Medis Suite 3.0, Medis medical imaging systems, Leiden, The Netherlands). LV contours were semi-automatically drawn in the short-axis images in the end-diastolic and end-systolic phase, to quantify the end-diastolic LV mass, LV end-diastolic and end-systolic volumes, LV stroke volume, LV ejection fraction, cardiac output and cardiac index. GLS was the average of the peak systolic strain on 2-, 3- and 4-chamber cines. GCS was the peak systolic strain in the mid-ventricular short-axis cines.

LV diastolic strain parameters included the global longitudinal early peak diastolic strain rate (GLSR-E) (average of the early peak diastolic strain rate in 2-, 3- and 4-chamber view) and the global circumferential early peak diastolic strain rate (GCSR-E) (the early peak diastolic strain rate in the mid-ventricular short-axis cines). $\mathrm{LV}$ diastolic function parameters derived from 4D velocity-encoded MR included the ratio of the transmitral early (E) and late (A) peak filling rate (E/A ratio), the peak deceleration slope of the $E$ wave (E dec peak), the estimated LV filling pressure (the ratio of the transmitral early peak velocity and the early peak diastolic mitral septal tissue velocity (Ea) measured on 4-chamber cines) and the estimated LV compliance (the ratio of LV end-diastolic volume and the estimated LV filling pressure) [19]. The transmitral flow rate curves were constructed after 
retrospective mitral valve tracking, perpendicular to the streamlines of inflow across the mitral valve, at the location of peak flow velocity, with correction for throughplane motion of the LV myocardial wall (MASS version 2015-EXP, Leiden University Medical Center, Leiden, The Netherlands) [20, 21].

\section{Aortic stiffness}

Aortic stiffness was quantified by the aortic pulse wave velocity, which was derived from a double-oblique aorta scout view and two free-breathing $2 \mathrm{D}$ velocity-encoded MR scans at the level of the ascending and abdominal aorta (venc $200 \mathrm{~cm} / \mathrm{s}$ and $150 \mathrm{~cm} / \mathrm{s}$, respectively; TE/ TR $2.5 / 4.4 \mathrm{~ms}$, FA $20^{\circ}$, FOV $350 \times 282 \mathrm{~mm}^{2}$, slice thickness $8 \mathrm{~mm}$, acquired voxel size $2.8 \times 2.8 \mathrm{~mm}^{2}$, temporal resolution $10 \mathrm{~ms}$ ). The aortic pulse wave velocity was calculated by dividing the distance between ascending and abdominal aorta by the transit time of the systolic wave front (MASS version 2015-EXP, Leiden University Medical Center, Leiden, The Netherlands and in-house developed software) [22].

\section{Myocardial steatosis}

Myocardial steatosis was examined using ECG-triggered, respiratory-navigated cardiac proton-magnetic resonance spectroscopy $\left({ }^{1} \mathrm{H}\right.$-MRS) in a voxel of $40 \times 15 \times 25 \mathrm{~mm}^{3}$ in the mid-ventricular septum, using a high permittivity pad on the thorax [TE $35 \mathrm{~ms}$, TR 3.5 or $9 \mathrm{~s}$ (water-suppressed and non-water suppressed acquisition, respectively), acquired samples 2048 (spectral resolution $0.73 \mathrm{~Hz} /$ sample), number of signal averages 64 or 6 (water-suppressed and non-water suppressed acquisition, respectively)] [23]. Starting values for the fit of the acquired spectrum were: triglyceride methyl $\left(\mathrm{CH}_{3}\right)$ 0.9 ppm, triglyceride methylene $\left(\mathrm{CH}_{2}\right)^{\mathrm{n}} 1.3 \mathrm{ppm}, \mathrm{COO}-$ $\mathrm{CH}_{2} 2.05 \mathrm{ppm}$, creatine $3.05 \mathrm{ppm}$, trimethylamines (TMA) $3.25 \mathrm{ppm}$. The myocardial triglyceride content was quantified as the amplitude of $\left(\mathrm{CH}_{2}\right)^{\mathrm{n}}$ divided by the amplitude of unsuppressed water, multiplied by $100 \%$ [24] (in-house developed software and the Java-based MR user interface, jMRUI v5.0; MRUI Consortium) [25, 26].

\section{Myocardial diffuse fibrosis}

Myocardial diffuse fibrosis was quantified using native and post-contrast modified Look-Locker inversion recovery (MOLLI) T1 mapping, obtained in short-axis orientation at the mid-ventricular level (TE/TR 1.1/2.3 ms, FA $20^{\circ}$, FOV $350 \times 300 \mathrm{~mm}^{2}$, slice thickness $8 \mathrm{~mm}$, acquired voxel size $2.1 \times 2.1 \mathrm{~mm}^{2}$, SENSE factor 2). Post-contrast T1 mapping was acquired 20-25 min after administration of $0.15 \mathrm{mmol}$ gadoterate meglumine $(0.5 \mathrm{mmol} /$ mL Dotarem; Guerbet Villepinte, France) per kilogram of body weight. Because of ongoing optimization of the T1 mapping protocols throughout the study, native and post-contrast MOLLI acquisition schemes were adjusted (for the European T2D patients: $3 \mathrm{~b}(3 \mathrm{~b}) 3 \mathrm{~b}(3 \mathrm{~b}) 5 \mathrm{~b}$ and $3 \mathrm{~b}(3 \mathrm{~b}) 3 \mathrm{~b}(3 \mathrm{~b}) 5 \mathrm{~b}$; for the European controls: $3 b(3 s) 3 b(3 s) 5 b$ and $3 b(3 s) 3 b(3 s) 5 b$; for the South Asian T2D patients and controls: $5 \mathrm{~s}(3 \mathrm{~s}) 3 \mathrm{~s}$ and $4 \mathrm{~s}(1 \mathrm{~s}) 3 \mathrm{~s}(1 \mathrm{~s}) 2 \mathrm{~s}$, respectively). T1 relaxation times were measured in the mid-ventricular septum, after manual correction for motion (QMap 2.2.18, Medis Suite 3.0, Medis medical imaging systems, Leiden, The Netherlands).

\section{Statistical analysis}

Clinical characteristics, adiposity and cardiovascular parameters were presented for the T2D and control group, for Europeans and South Asians separately, and were expressed as mean $\pm \mathrm{SD}$, medians (interquartile ranges) or numbers (percentages). We assessed the differences in clinical characteristics and cardiovascular parameters between T2D patients and controls, for Europeans and South Asians, using the Student's t-test or the Fisher's exact test, and reported the differences in adiposity parameters as means (95\% CI). Differences in cardiovascular parameters between T2D patients and controls, for South Asians and Europeans, were further examined using ANCOVA with adjustment for age, sex, systolic and diastolic blood pressure and smoking status (currently vs. never or formerly). Ethnic group comparisons in the association of T2D with cardiovascular remodeling were made by adding the interaction term between ethnicity and diabetes status to the model [10]. We assessed the normal distribution of the data visually. All statistical tests were two-sided and $P<0.05$ was considered significant. Statistical analyses were performed using SPSS 23 (IBM Corp, New York, United States).

\section{Results}

\section{Clinical characteristics and adiposity parameters}

In the present study, 48 of the 50 European T2D patients who participated in the trial NCT01761318 [17] were included ( $\mathrm{n}=1$ was excluded because of type 1 diabetes and $n=1$ was excluded because of missing CMR data due to claustrophobia). South Asian T2D patients with age $>65$ years who participated in the trial NCT02660047 [18] were excluded in this study, as we were unable to enroll South Asian healthy controls in this age category due to the high prevalence of cardiometabolic risk factors among older South Asian individuals. In the current study, 33 of the 47 South Asian T2D patients were included ( $n=6$ were excluded because of age $>65$ years, subsequently $\mathrm{n}=6$ were excluded due to significant 
coronary artery disease and $n=2$ due to mitral valve insufficiency and/or stenosis on CMR).

In total, the present study comprised 131 individuals ( $\mathrm{n}=81$ patients with T2D and $\mathrm{n}=50$ healthy controls). In the European cohort $(\mathrm{n}=77), 48$ patients [mean \pm SD age: $59.5 \pm 6.6$ years, diabetes duration: $10.7 \pm 6.2$ years, $28(58 \%)$ men] and 29 controls [mean \pm SD age: $57.6 \pm 7.8$ years, $15(52 \%)$ men] were included. The South Asian study population $(\mathrm{n}=54)$ consisted of 33 patients [51.3 \pm 9.0 years, diabetes duration: $15.1 \pm 9.4$ years, $12(36 \%)$ men] and 21 controls $[48.3 \pm 8.1$ years, $6(29 \%)$ men]. Baseline characteristics are presented in Table 1. Whereas the T2D and control groups were similar according to age and sex distribution for both the South Asian and European cohort, the South Asian compared with the European study population was younger $(50.1 \pm 8.7$ vs. $58.8 \pm 7.0$ years, $P<0.001)$ and consisted of more women [18/54 (33\%) vs. $43 / 77$ (56\%) men, $P=0.013]$. The European and South Asian control groups were similar regarding smoking status $(P=0.297)$, systolic and diastolic blood pressure $(P=0.467$ and 0.973 , respectively), triglycerides $(P=0.582)$, total cholesterol $(P=0.285)$, LDL-cholesterol $(P=0.848)$ and HbA1c $(P=0.925)$, except that high-density lipoprotein (HDL)-cholesterol was lower among the South Asians $(P=0.010)$. For the South Asian as compared with the European T2D patients, diabetes duration was longer $(P=0.012)$, the daily insulin dose tended to be higher $(P=0.056)$, the urinary albumin/creatinine ratio was higher $(P=0.045)$ and total cholesterol was lower $(P=0.046)$, whereas HbA1c was similar $(P=0.801)$.

In both the European and South Asian populations, obesity and adipose tissue parameters, blood pressure, cholesterol and glycemic levels were higher in the T2D compared with the control group (Table 1). Differences in obesity and adipose tissue parameters between the T2D and control group in the European and South Asian population were $7.8 \mathrm{~kg} / \mathrm{m}^{2}(6.1 ; 9.5)$ and $6.2 \mathrm{~kg} / \mathrm{m}^{2}(4.1$; 8.3) for BMI, $24 \mathrm{~cm}(20 ; 28)$ and $19 \mathrm{~cm}(14 ; 24)$ for waist circumference, $0.15(0.11 ; 0.18)$ and $0.10(0.05 ; 0.14)$ for waist-hip ratio, $9.8 \%(5.8 ; 13.8)$ and $5.0 \%(0.3 ; 9.7)$ for total body fat percentage, $146 \mathrm{~cm}^{2}(96 ; 197)$ and $96 \mathrm{~cm}^{2}$ (28; 164) for abdominal SAT and $131 \mathrm{~cm}^{2}(102 ; 160)$ and $79 \mathrm{~cm}^{2}(55 ; 102)$ for VAT, respectively.

\section{Association between T2D and cardiovascular parameters in Europeans and South Asians}

In univariable analyses, for both Europeans and South Asians, T2D patients as compared with controls had LV structural alterations (higher LV concentricity), with impairments in LV diastolic function (lower E/A ratio and higher LV filling pressure) and aortic stiffness (higher aortic pulse wave velocity) (Tables 2 and 3 ). The E dec peak, Ea, LV compliance and GLS were impaired in the T2D patients compared with the controls among Europeans but not among South Asians. Cardiovascular parameters for the T2D patients and controls are presented in Figs. 1, 2 and 3.

In multivariable analyses, in both European and South Asian T2D patients the E/A ratio remained lower and LV concentricity persisted to be higher compared with controls, but there were no differences in the E dec peak, GLS or aortic pulse wave velocity (Table 4). Furthermore, in multivariable analyses, the LV filling pressure was increased or tended to be higher in European and South Asian T2D patients, respectively, compared with their controls. In European but not in South Asian T2D patients, additionally, Ea and LV compliance were lower in comparison with their controls $(P=0.095$ and 0.008 for interaction by ethnicity, respectively). In European T2D patients the stroke volume was reduced, with a slight decrease in cardiac index, whereas in South Asian T2D patients cardiac index was preserved in comparison with their control groups $(P=0.012$ for interaction by ethnicity). In European T2D patients the LV concentricity was increased in parallel with lower end-diastolic volumes ( $P=0.001$ for interaction by ethnicity), whereas in South Asian T2D patients the increased LV concentricity was in parallel with a higher LV mass $(P=0.005$ for interaction by ethnicity). In South Asian but not in European T2D patients compared with their controls, the myocardial cell and extracellular volumes were higher $(P=0.003$ and 0.071 for interaction by ethnicity, respectively). Because of a larger increase in the myocardial cell volume than in the extracellular volume, the extracellular volume fraction was slightly lower in the South Asian T2D patients than in the controls $(P=0.114$ for interaction by ethnicity). In European but not South Asian T2D patients, the myocardial triglyceride content was higher and native T1 was lower in comparison with their controls $(P=0.002$ and 0.078 for interaction by ethnicity, respectively).

\section{Discussion}

In both Europeans and South Asians, the E/A ratio was lower in relation to T2D, whereas global systolic and diastolic strain parameters and aortic pulse wave velocity were similar in the T2D patients and controls in multivariable analysis. Furthermore, South Asian T2D patients had a higher LV mass with a lower extracellular volume fraction, whilst European T2D patients had a higher myocardial triglyceride content than their control group.

\section{LV functional and structural remodeling in T2D}

In our study, in both the European and South Asian population, T2D was associated with reduced LV diastolic function and increased LV concentricity. LV diastolic 
Table 1 Clinical characteristics and adiposity parameters

\begin{tabular}{|c|c|c|c|c|}
\hline & \multicolumn{2}{|l|}{ Europeans } & \multicolumn{2}{|l|}{ South Asians } \\
\hline & $T 2 D(n=48)$ & Controls $(n=29)$ & T2D $(n=33)$ & Controls $(n=21)$ \\
\hline Age, years & $59.5 \pm 6.6$ & $57.6 \pm 7.8$ & $51.3 \pm 9.0$ & $48.3 \pm 8.1$ \\
\hline Men, no. (\%) & $28(58 \%)$ & $15(52 \%)$ & $12(36 \%)$ & $6(29 \%)$ \\
\hline Current smoker, no. (\%) & $9(19 \%)$ & $1(3 \%)$ & $5(15 \%)$ & $3(14 \%)$ \\
\hline $\mathrm{BSA}, \mathrm{m}^{2}$ & $2.1 \pm 0.2^{*}$ & $1.9 \pm 0.2$ & $1.9 \pm 0.2^{*}$ & $1.7 \pm 0.2$ \\
\hline $\mathrm{BMl}, \mathrm{kg} / \mathrm{m}^{2}$ & $32 \pm 4^{*}$ & $24 \pm 3$ & $30 \pm 4^{*}$ & $24 \pm 3$ \\
\hline Waist circumference, cm & $110 \pm 9^{*}$ & $87 \pm 9$ & $101 \pm 10^{*}$ & $82 \pm 7$ \\
\hline Men & $109 \pm 8$ & $91 \pm 7$ & $103 \pm 8$ & $86 \pm 8$ \\
\hline Women & $112 \pm 10$ & $82 \pm 9$ & $100 \pm 11$ & $81 \pm 7$ \\
\hline Waist-hip ratio & $1.03 \pm 0.07^{*}$ & $0.88 \pm 0.08$ & $0.96 \pm 0.09^{*}$ & $0.86 \pm 0.07$ \\
\hline Men & $1.05 \pm 0.06$ & $0.93 \pm 0.04$ & $1.00 \pm 0.08$ & $0.93 \pm 0.05$ \\
\hline Women & $1.00 \pm 0.07$ & $0.83 \pm 0.07$ & $0.94 \pm 0.08$ & $0.84 \pm 0.07$ \\
\hline Systolic blood pressure, $\mathrm{mmHg}$ & $141 \pm 15^{*}$ & $126 \pm 12$ & $141 \pm 21^{*}$ & $124 \pm 14$ \\
\hline Diastolic blood pressure, $\mathrm{mmHg}$ & $87 \pm 9^{*}$ & $80 \pm 8$ & $85 \pm 11$ & $80 \pm 12$ \\
\hline Heart rate, beats/min & $71 \pm 12^{*}$ & $59 \pm 9$ & $69 \pm 12^{*}$ & $61 \pm 8$ \\
\hline Triglycerides, mmol/L & $2.2 \pm 1.3^{*}$ & $1.0 \pm 0.4$ & $1.9 \pm 1.5^{*}$ & $0.9 \pm 0.3$ \\
\hline Total cholesterol, mmol/L & $4.8 \pm 1.0^{*}$ & $5.7 \pm 1.1$ & $4.4 \pm 1.0^{*}$ & $5.4 \pm 0.8$ \\
\hline HDL-cholesterol, mmol/L & $1.3 \pm 0.3^{*}$ & $1.9 \pm 0.5$ & $1.2 \pm 0.3^{*}$ & $1.6 \pm 0.3$ \\
\hline LDL-cholesterol, mmol/L & $2.6 \pm 0.9^{*}$ & $3.3 \pm 1.0$ & $2.2 \pm 0.9^{*}$ & $3.4 \pm 0.7$ \\
\hline Glycated hemoglobin, $\mathrm{mmol} / \mathrm{mol}$ & $65.5 \pm 10.8^{*}$ & $35.5 \pm 2.7$ & $66.2 \pm 11.3^{*}$ & $35.5 \pm 2.4$ \\
\hline Serum creatinine, $\mu \mathrm{mol} / \mathrm{L}$ & $70 \pm 18$ & $76 \pm 14$ & $67 \pm 17$ & $73 \pm 18$ \\
\hline Urinary albumin/creatinine ratio, mg/mmol & $0.7(0.0 ; 2.7)$ & - & $1.9(0.5 ; 6.4)$ & - \\
\hline Microalbuminuria, no. (\%) & $9(19 \%)$ & - & $10(30 \%)$ & - \\
\hline Macroalbuminuria, no. (\%) & $1(2 \%)$ & - & $3(9 \%)$ & - \\
\hline Diabetes duration, years & $10.7 \pm 6.2$ & - & $15.1 \pm 9.4$ & - \\
\hline Metformin, no. (\%) & $48(100 \%)$ & - & $32(97 \%)$ & - \\
\hline Insulin, no. (\%) & $31(65 \%)$ & - & $23(70 \%)$ & - \\
\hline Insulin dose, units/day & $44(32 ; 94)$ & - & $78(45 ; 108)$ & - \\
\hline Lipid lowering drugs, no. (\%) & $39(81 \%)$ & - & $25(76 \%)$ & - \\
\hline Antihypertensive drugs, no. (\%) & 37 (77\%) & - & $20(61 \%)$ & - \\
\hline ACE-inhibitors, no. (\%) & $17(35 \%)$ & - & $8(24 \%)$ & - \\
\hline Total body fat, $\%$ & $36.7 \pm 9.3^{*}$ & $26.9 \pm 7.3$ & $37.3 \pm 9.1^{*}$ & $32.3 \pm 7.1$ \\
\hline Men & $29.7 \pm 3.6$ & $21.9 \pm 3.1$ & $27.3 \pm 4.9$ & $23.3 \pm 4.2$ \\
\hline Women & $46.4 \pm 5.0$ & $32.2 \pm 6.7$ & $42.5 \pm 5.7$ & $36.0 \pm 4.0$ \\
\hline Abdominal SAT, $\mathrm{cm}^{2}$ & $346 \pm 125^{*}$ & $200 \pm 69$ & $344 \pm 128^{*}$ & $248 \pm 109$ \\
\hline Men & $277 \pm 93$ & $173 \pm 55$ & $309 \pm 109$ & $204 \pm 109$ \\
\hline Women & $442 \pm 97$ & $228 \pm 73$ & $364 \pm 136$ & $265 \pm 107$ \\
\hline VAT, $\mathrm{cm}^{2}$ & $207 \pm 75^{*}$ & $76 \pm 34$ & $152 \pm 48^{*}$ & $73 \pm 30$ \\
\hline Men & $214 \pm 63$ & $89 \pm 31$ & $158 \pm 49$ & $94 \pm 19$ \\
\hline Women & $197 \pm 89$ & $62 \pm 32$ & $148 \pm 48$ & $65 \pm 29$ \\
\hline
\end{tabular}

Mean $\pm S D$, medians (interquartile range) or numbers (percentages) are presented. ${ }^{*} P<0.05$ vs. controls. Microalbuminuria and macroalbuminuria: urinary albumin/ creatinine ratio (ACR) $3-30 \mathrm{mg} / \mathrm{mmol}$ and $>30 \mathrm{mg} / \mathrm{mmol}$, respectively. Missing values: $\mathrm{n}=1$ for total body fat in the South Asian T2D group

$A C E$ angiotensin-converting enzyme, BMI body mass index, BSA body surface area, HDL and LDL high-density and low-density lipoprotein, VAT and SAT visceral and subcutaneous adipose tissue

function in T2D may be impaired due to disturbances in myocardial substrate utilization and myocardial energetics [11, 27]. More recently, the pro-inflammatory state in T2D has been proposed as an important contributing factor to the increased diastolic LV stiffness [28]. LV diastolic function may be most susceptible to energy shortage [29], whereas abnormalities in LV systolic function may develop once myocardial energetics are substantially 
Table 2 Cardiovascular parameters in Europeans

T2D $(n=48)$ Controls $(n=29)$

LV diastolic function

\begin{tabular}{|c|c|c|}
\hline $\mathrm{E}, \mathrm{mL} / \mathrm{s}$ & $326 \pm 97$ & $352 \pm 55$ \\
\hline $\mathrm{A}, \mathrm{mL} / \mathrm{s}$ & $366 \pm 71^{*}$ & $301 \pm 75$ \\
\hline E/A ratio & $0.93 \pm 0.38^{*}$ & $1.24 \pm 0.36$ \\
\hline E dec peak, $\mathrm{mL} / \mathrm{s}^{2} \times 10^{-3}$ & $-2.7 \pm 1.0^{*}$ & $-3.2 \pm 0.7$ \\
\hline $\mathrm{Ea}, \mathrm{cm} / \mathrm{s}$ & $5.9 \pm 1.7^{*}$ & $7.7 \pm 1.9$ \\
\hline $\begin{array}{l}\text { Estimate of LV filling pressure, } \\
\text { mmHg }\end{array}$ & $7.6 \pm 2.6^{*}$ & $5.1 \pm 1.7$ \\
\hline $\begin{array}{l}\text { Estimate of LV compliance, mL/ } \\
\qquad \mathrm{mmHg}\end{array}$ & $21.3 \pm 9.4^{*}$ & $33.4 \pm 11.2$ \\
\hline GLSR-E, 1/s & $0.78 \pm 0.23$ & $0.87 \pm 0.28$ \\
\hline GCSR-E, 1/s & $1.15 \pm 0.37$ & $1.22 \pm 0.37$ \\
\hline \multicolumn{3}{|l|}{ LV systolic function } \\
\hline Ejection fraction, \% & $55 \pm 5$ & $56 \pm 6$ \\
\hline GLS, \% & $-19.3 \pm 2.7^{*}$ & $-21.1 \pm 3.3$ \\
\hline GCS, \% & $-26.1 \pm 4.5$ & $-26.5 \pm 3.9$ \\
\hline \multicolumn{3}{|l|}{ Hemodynamics } \\
\hline Stroke volume, mL & $78 \pm 17^{*}$ & $88 \pm 17$ \\
\hline Cardiac output, L/min & $5.4 \pm 1.0$ & $5.2 \pm 1.1$ \\
\hline Cardiac index, L/min/m² & $2.5 \pm 0.4^{*}$ & $2.7 \pm 0.5$ \\
\hline \multicolumn{3}{|l|}{ Aortic stiffness } \\
\hline Aortic pulse wave velocity, m/s & $8.5 \pm 2.2^{*}$ & $7.5 \pm 1.5$ \\
\hline \multicolumn{3}{|l|}{ LV structure } \\
\hline End-diastolic volume, mL & $142 \pm 29^{*}$ & $156 \pm 26$ \\
\hline Mass, $g$ & $107 \pm 23$ & $96 \pm 24$ \\
\hline Concentricity, g/mL & $0.76 \pm 0.12^{*}$ & $0.61 \pm 0.09$ \\
\hline \multicolumn{3}{|l|}{ Myocardial tissue characteristics } \\
\hline Myocardial Tg content, \% & $1.19 \pm 0.53^{*}$ & $0.58 \pm 0.18$ \\
\hline Native T1, ms & $1197 \pm 44^{*}$ & $1230 \pm 28$ \\
\hline Extracellular volume fraction, \% & $26.3 \pm 2.5$ & $26.9 \pm 2.7$ \\
\hline Extracellular volume, mL & $27 \pm 6$ & $24 \pm 5$ \\
\hline Cell volume, $\mathrm{mL}$ & $75 \pm 18$ & $67 \pm 18$ \\
\hline
\end{tabular}

Mean \pm SD. ${ }^{*} P<0.05$ vs. controls. Missing values in the T2D group: $n=1$ for all flow-derived LV diastolic function parameters, $n=3 \mathrm{E}$ dec peak, $n=1 \mathrm{GLSR}-\mathrm{E}$, $\mathrm{n}=1$ aortic pulse wave velocity, $\mathrm{n}=1$ myocardial Tg content, $\mathrm{n}=4$ native T1, $\mathrm{n}=5$ extracellular volume, cell volume, fibrosis volume; in the control group: $\mathrm{n}=1$ for all flow-derived LV diastolic function parameters

Ea early peak diastolic mitral septal tissue velocity, E and $A$ transmitral early and late peak filling rate, $E$ dec peak peak deceleration slope of $E, G L S$ and GLSR-E global longitudinal strain and early peak diastolic strain rate, GCS and GCSR-E global circumferential strain and early peak diastolic strain rate, LV left ventricular, $T g$ triglyceride

disturbed. Furthermore, in our study, T2D was not associated with an increase in aortic stiffness, although oxidative stress due to hyperglycemia and vascular inflammation have been related to impairments in aortic function [30, 31]. Possibly, aortic stiffening, similar as LV systolic dysfunction, may arise in more advanced T2D.

The prevalence of diastolic dysfunction in asymptomatic T2D patients has been reported to be at least $50 \%$ [32]. Notably, several studies have indicated that
Table 3 Cardiovascular parameters in South Asians

T2D $(n=33)$ Controls $(n=21)$

\begin{tabular}{|c|c|c|}
\hline \multicolumn{3}{|l|}{ LV diastolic function } \\
\hline $\mathrm{E}, \mathrm{mL} / \mathrm{s}$ & $339 \pm 109$ & $333 \pm 67$ \\
\hline $\mathrm{A}, \mathrm{mL} / \mathrm{s}$ & $302 \pm 64^{*}$ & $242 \pm 54$ \\
\hline E/A ratio & $1.15 \pm 0.37^{*}$ & $1.42 \pm 0.36$ \\
\hline $\mathrm{E}$ dec peak, $\mathrm{mL} / \mathrm{s}^{2} \times 10^{-3}$ & $-2.9 \pm 1.2$ & $-3.2 \pm 0.7$ \\
\hline $\mathrm{Ea}, \mathrm{cm} / \mathrm{s}$ & $5.9 \pm 2.0$ & $6.8 \pm 1.9$ \\
\hline $\begin{array}{l}\text { Estimate of LV filling pressure, } \\
\mathrm{mmHg}\end{array}$ & $6.9 \pm 3.0^{*}$ & $5.0 \pm 1.6$ \\
\hline $\begin{array}{l}\text { Estimate of LV compliance, } \mathrm{mL} / \\
\mathrm{mmHg}\end{array}$ & $20.5 \pm 9.0$ & $24.0 \pm 7.7$ \\
\hline GLSR-E, 1/s & $0.88 \pm 0.22$ & $0.98 \pm 0.16$ \\
\hline GCSR-E, 1/S & $1.32 \pm 0.34$ & $1.31 \pm 0.24$ \\
\hline \multicolumn{3}{|l|}{ LV systolic function } \\
\hline Ejection fraction, \% & $58 \pm 6$ & $60 \pm 5$ \\
\hline GLS, \% & $-20.4 \pm 2.8$ & $-21.7 \pm 1.7$ \\
\hline GCS, \% & $-27.6 \pm 4.3$ & $-27.6 \pm 3.4$ \\
\hline \multicolumn{3}{|l|}{ Hemodynamics } \\
\hline Stroke volume, $\mathrm{mL}$ & $70 \pm 14$ & $66 \pm 12$ \\
\hline Cardiac output, L/min & $4.8 \pm 1.0^{*}$ & $4.0 \pm 0.7$ \\
\hline Cardiac index, L/min $/ \mathrm{m}^{2}$ & $2.5 \pm 0.4$ & $2.3 \pm 0.3$ \\
\hline \multicolumn{3}{|l|}{ Aortic stiffness } \\
\hline Aortic pulse wave velocity, m/s & $7.9 \pm 2.0^{*}$ & $6.5 \pm 1.1$ \\
\hline \multicolumn{3}{|l|}{ LV structure } \\
\hline End-diastolic volume, $\mathrm{mL}$ & $123 \pm 25$ & $110 \pm 19$ \\
\hline Mass, g & $93 \pm 20^{*}$ & $66 \pm 15$ \\
\hline Concentricity, g/mL & $0.77 \pm 0.14^{*}$ & $0.60 \pm 0.10$ \\
\hline \multicolumn{3}{|l|}{ Myocardial tissue characteristics } \\
\hline Myocardial Tg content, \% & $0.93 \pm 0.54$ & $0.84 \pm 0.43$ \\
\hline Native T1, ms & $1255 \pm 37$ & $1263 \pm 42$ \\
\hline Extracellular volume fraction, \% & $26.2 \pm 3.0^{*}$ & $28.2 \pm 2.6$ \\
\hline Extracellular volume, $\mathrm{mL}$ & $23 \pm 5^{*}$ & $18 \pm 4$ \\
\hline Cell volume, $\mathrm{mL}$ & $66 \pm 16^{*}$ & $45 \pm 11$ \\
\hline
\end{tabular}

Mean \pm SD. ${ }^{*} P<0.05$ vs. controls. Missing values in the T2D group: $\mathrm{n}=1$ native $\mathrm{T} 1$ and extracellular volume, cell volume, fibrosis volume; in the control group: $\mathrm{n}=1$ for myocardial Tg content. For abbreviations see Table 2

GLS, in addition to diastolic function parameters, may be impaired in T2D patients [14, 33-35]. Also, abnormalities in GLS have been demonstrated even in T2D patients with normal diastolic function and, in this regard, some argue that reduced LV longitudinal contractility rather than diastolic dysfunction should be regarded as the first marker of diabetic cardiomyopathy [36]. Nonetheless, in multivariable analysis, we did not observe a reduction in GLS in T2D patients as compared with controls, neither in the European nor in the South Asian population.

Importantly, the increased LV concentricity in European T2D patients was due to a reduction in LV enddiastolic volume, whereas the higher LV concentricity 


\section{Europeans}
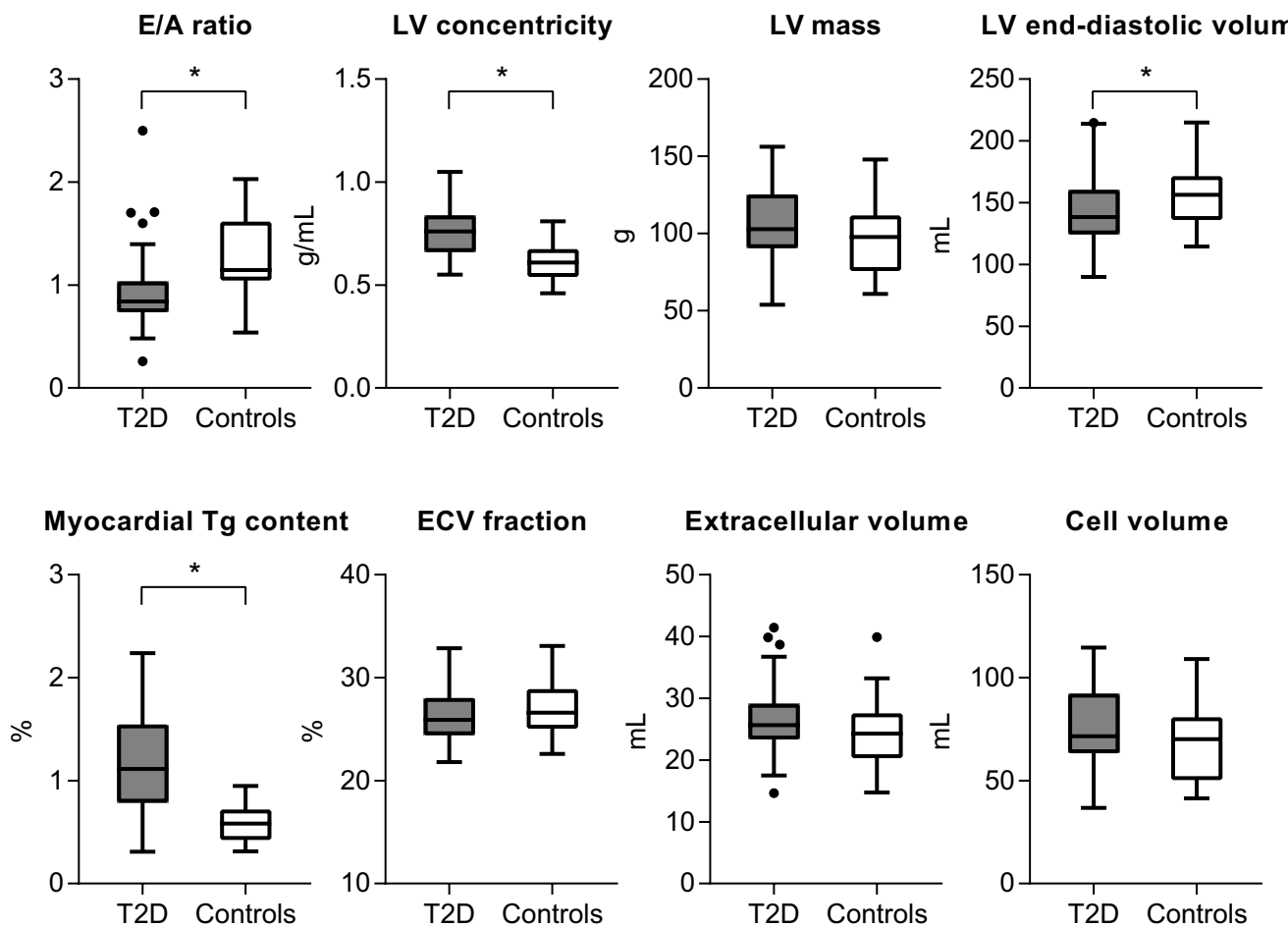

Fig. 1 Cardiovascular parameters (boxplots depicting median, interquartile ranges and outliers) in European T2D patients ( $n=48)$ and controls $(n=29)\left({ }^{*} P<0.05\right)$. In European T2D patients, the E/A ratio was lower than in the controls, LV concentricity was higher in parallel with a lower LV end-diastolic volume, and the myocardial triglyceride content was higher. E/A ratio of the transmitral early and late peak filling rate, ECV extracellular volume, LV left ventricular, $T g$ triglyceride

among South Asian T2D patients was related to an increase in LV mass. These observations imply that the higher LV concentricity in T2D may be the result of impaired LV diastolic function (with therefore incomplete LV relaxation, reduced LV filling and lower LV end-diastolic volumes) and/or LV hypertrophic remodeling [37]. In the Multi-Ethnic Study of Atherosclerosis (MESA) study, the relationships of T2D and impaired fasting glucose to LV mass, end-diastolic volume and stroke volume differed between white, black, Hispanic and Chinese individuals [38]. Similar to our study, the MESA study reported a lower LV end-diastolic volume in white T2D patients, whereas an increased LV mass in relation to T2D, after adjustment for demographic and anthropomorphic factors, was solely observed in the black and Hispanic groups [38]. Notably, it has been suggested that LV hypertrophy in T2D may be partly due to excessive sympathetic activity, driven by insulin resistance [39]. In this regard, we speculate that LV mass was increased in South Asian but not in European T2D patients, in part because of the slightly higher degree of insulin resistance. Furthermore, population studies have shown that South Asian individuals are susceptible of developing T2D at younger age than other ethnic groups [40]. Accordingly, in our study, the diabetes duration was longer for the South Asian compared with the European population. The difference in diabetes duration may have contributed to the increased LV mass as observed in the South Asian but not in the European T2D patients.

A previous community-based study reported that T2D may be more detrimental for cardiac function among South Asians compared with other ethnic groups [10]. Nevertheless, in our study, the degree of LV diastolic dysfunction seemed to be slightly higher for the European than for the South Asian T2D patients, as indicated by the lower Ea and LV compliance and significantly higher LV filling pressure in relation to T2D in the European but not in the South Asian cohort. Obesity as well as T2D has been shown to be associated with LV diastolic dysfunction [41, 42]. The relatively high degree of adiposity in the European T2D patients in comparison with their controls may have accounted for the slightly higher degree of LV diastolic dysfunction than in the South Asian T2D patients. 


\section{South Asians}
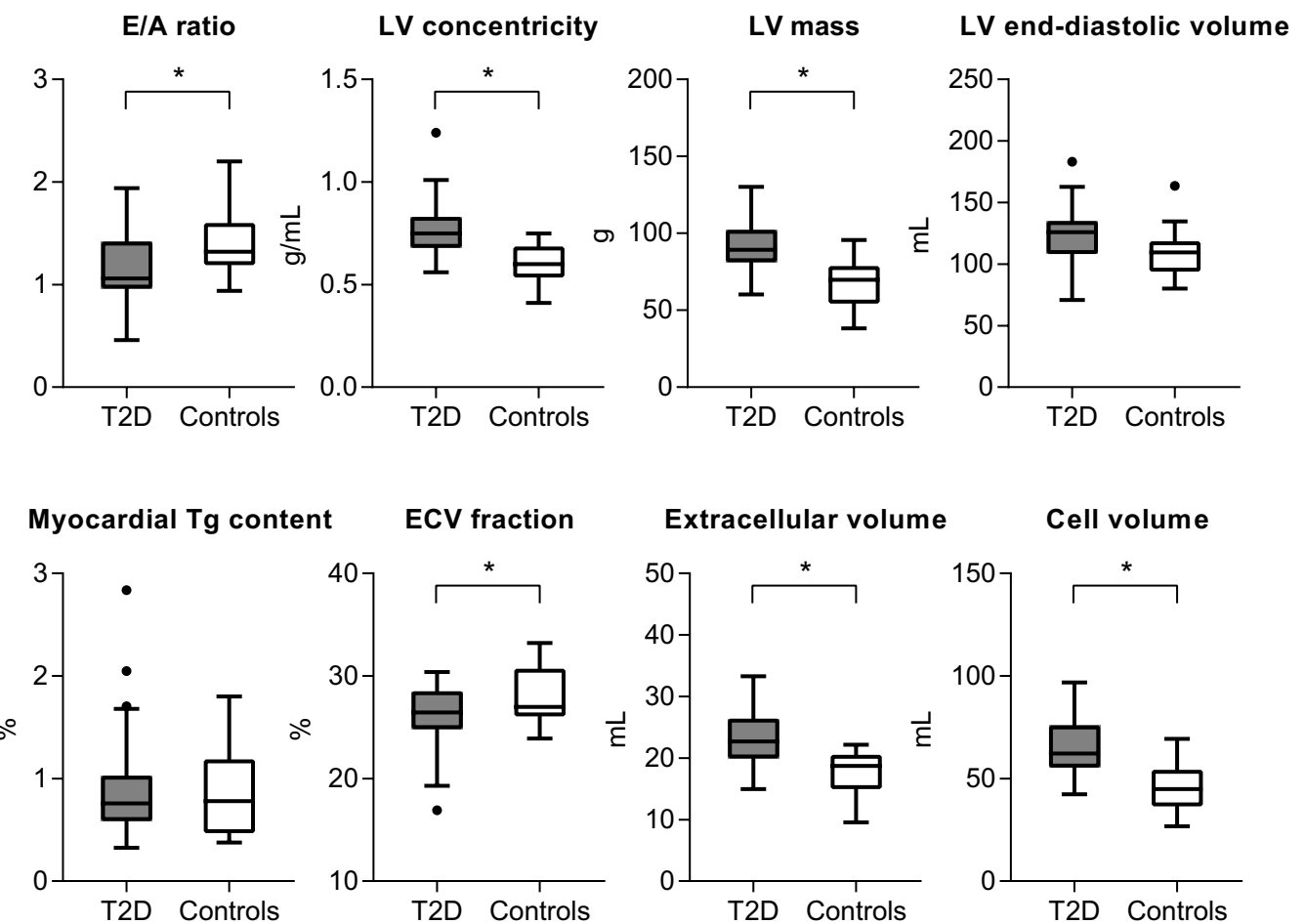

Fig. 2 Cardiovascular parameters (boxplots depicting median, interquartile ranges and outliers) in South Asian T2D patients ( $n=33$ ) compared with controls $(n=21)(* P 0.05)$. In South Asian T2D patients, the E/A ratio was lower than in the controls and LV concentricity was higher in parallel with a higher LV mass. As both the LV extracellular volume and myocardial cell volume were higher, the ECV fraction was slightly lower in South Asian T2D patients than in controls. Abbreviations as in Fig. 1

\section{Role of myocardial steatosis in diabetic cardiomyopathy}

Both in imaging studies in T2D patients and in histological studies in diabetic mice, T2D has been demonstrated to be associated with myocardial steatosis [13, 43-45]. Myocardial lipid overstorage is presumed to induce LV diastolic impairments due to the lipotoxic effects of intermediates such as diacylglycerol and ceramide [44-46]. Also, ectopic fat accumulation in the myocardium may reflect altered substrate utilization due to insulin resistance, with an increase in fatty acid oxidation [11, 27]. In keeping with previous findings, we observed a twofold increase in myocardial triglyceride content in T2D patients as compared with healthy controls within the European cohort [13]. Interestingly, the myocardial triglyceride content seemed to be increased in the healthy controls of South Asian descent compared with those of European origin, to similar levels as in the T2D patients, despite the strict screening for both T2D and prediabetes. Myocardial triglyceride content in South Asians as compared with Europeans has been previously assessed in young men and middle-aged overweight men, where no differences were found despite the observed higher systemic insulin resistance in those studies [47, 48].
Presumably, myocardial and systemic insulin sensitivity may not be necessarily interrelated. Accordingly, in a previous study on the relation between myocardial triglyceride content and LV diastolic function in healthy controls, increasing age, but not whole-body insulin resistance, correlated with myocardial steatosis and reduced LV diastolic function [49]. Also, it has to be noted that myocardial triglyceride content in non-diabetic individuals reflects the rate of fatty acid uptake as well as oxidation, and may therefore be dependent on many other factors in addition to myocardial insulin sensitivity, for example the amount of circulating fatty acids, dietary carbohydrate intake, plasma glucose availability and muscular glycogen stores [50]. Although our data reaffirm the potential role of myocardial steatosis in diabetic cardiomyopathy, our results suggest that myocardial triglyceride accumulation may be present in non-diabetic individuals as well as T2D patients.

\section{Role of diffuse fibrosis in diabetic cardiomyopathy}

Previously, myocardial diffuse fibrosis as indicated by an increased extracellular volume fraction has been demonstrated in obese adolescents with or without 
a Europeans and South Asians

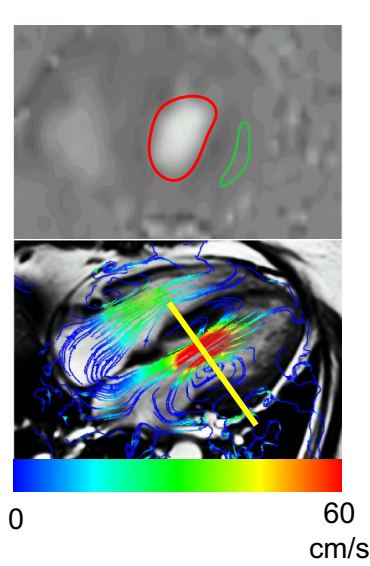

b South Asians

T2D patient
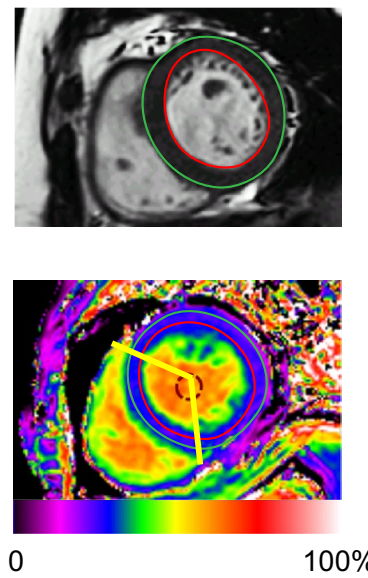

T2D patient

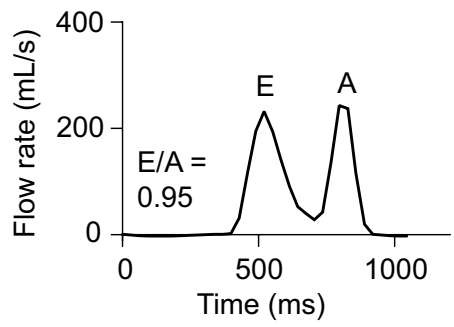

C Europeans

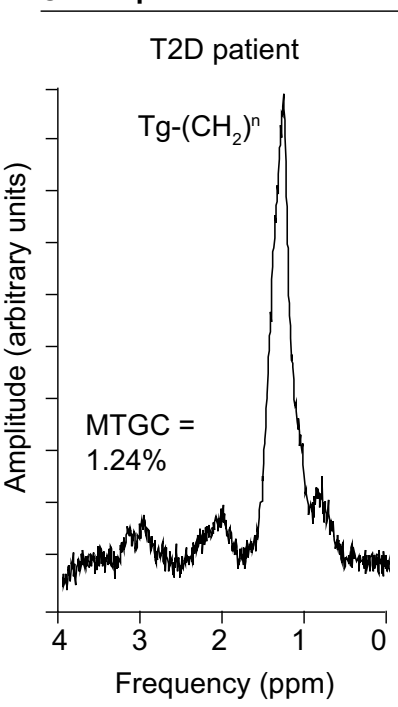

Control

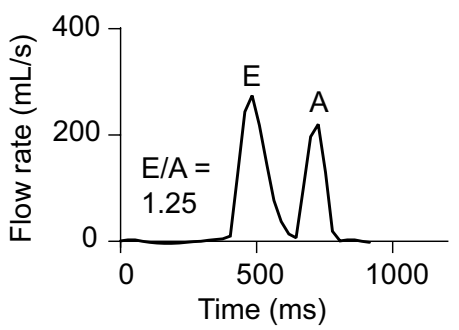

Control

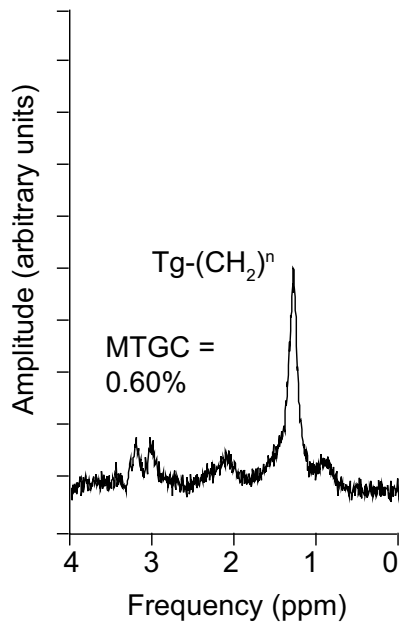

Fig. 3 Diabetic cardiomyopathy phenotype in Europeans and South Asians. a Impaired LV diastolic function, as indicated by a lower ratio of the transmitral early and late peak filling rate (E/A) was identified as a common characteristic of diabetic cardiomyopathy in Europeans and South Asians. The E/A ratio was measured using 4D velocity-encoded MR after retrospective mitral valve tracking and through-plane motion correction (left image). An example of the transmitral flow rate curve in a T2D patient (South Asian 62-year-old woman with E/A: 0.95) and control (South Asian 57-year-old women with E/A: 1.25) is provided (right images). b In South Asian but not in European T2D patients the LV mass, measured on short-axis cine (upper image), was higher than in the control group and the extracellular volume fraction, measured in the mid-ventricular septum using T1 mapping (lower image), was decreased. In the presented South Asian T2D patient, LV mass was $97 \mathrm{~g}$ and extracellular volume fraction was 27\%. c Among Europeans but not among South Asians the myocardial triglyceride content was different for T2D patients compared with controls. An example of cardiac proton-magnetic resonance spectroscopy ( ${ }^{1} \mathrm{H}$-MRS) in a 45-year-old woman with T2D (left image) and in a 48-year-old non-diabetic woman (right image) of European descent is provided (myocardial triglyceride content (MTGC): $1.24 \%$ and $0.60 \%$, respectively)

T2D, independent of blood pressure [16]. Interestingly, in a recent population-based study, the extracellular volume fraction was found to be reduced in T2D patients [51]. It has been suggested that antihypertensive medication, especially angiotensinconverting enzyme (ACE) inhibitors, may regress myocardial fibrotic remodeling in response to hypertension [52]. Our South Asian but not European T2D study population had an increased LV mass, paralleled by a reduced extracellular volume fraction. A majority of the patients were prescribed antihypertensive drugs, with almost halve of them using ACE-inhibitors. This may explain the considerable increase in myocardial cell volume in response to increased LV afterload, with only a slight increase of the LV extracellular volume. Although myocardial diffuse fibrosis may contribute to $\mathrm{LV}$ functional impairments in the early stages of $\mathrm{T} 2 \mathrm{D}$, 
Table 4 Association between T2D and cardiovascular parameters

\begin{tabular}{|c|c|c|c|}
\hline & \multicolumn{2}{|c|}{ Adjusted mean difference $(95 \% \mathrm{Cl})$ between T2D patients and controls } & \multirow{2}{*}{$\begin{array}{l}P \text { value } \\
\text { for interaction } \\
\text { by ethnicity }\end{array}$} \\
\hline & Europeans $(n=77)$ & South Asians $(n=54)$ & \\
\hline \multicolumn{4}{|l|}{ LV diastolic function } \\
\hline$E / A$ & $-0.20(-0.36,-0.04)$ & $-0.20(-0.36,-0.03)$ & 0.480 \\
\hline E dec peak, $\mathrm{mL} / \mathrm{s}^{2} \times 10^{-3}$ & $0.35(-0.13,0.83)$ & $-0.03(-0.54,0.49)$ & 0.576 \\
\hline $\mathrm{Ea}, \mathrm{cm} / \mathrm{s}$ & $-1.1(-1.9,-0.4)$ & $-0.4(-1.4,0.6)$ & 0.095 \\
\hline LV filling pressure, $\mathrm{mmHg}$ & $2.3(1.0,3.6)$ & $1.0(-0.4,2.4)$ & 0.300 \\
\hline LV compliance, $\mathrm{mL} / \mathrm{mmHg}$ & $-12.9(-18.6,-7.2)$ & $-1.5(-6.1,3.1)$ & 0.008 \\
\hline \multicolumn{4}{|l|}{ LV systolic function } \\
\hline $\mathrm{GLS}, \%$ & $0.6(-0.9,2.1)$ & $1.3(-0.2,2.8)$ & 0.708 \\
\hline \multicolumn{4}{|l|}{ Hemodynamics } \\
\hline Stroke volume, $\mathrm{mL}$ & $-10(-19,-1)$ & $3(-4,11)$ & 0.007 \\
\hline Cardiac output, L/min & $0.3(-0.3,0.8)$ & $0.8(0.3,1.3)$ & 0.067 \\
\hline Cardiac index, $\mathrm{L} / \mathrm{min} / \mathrm{m}^{2}$ & $-0.2(-0.4,0.0)$ & $0.1(-0.1,0.3)$ & 0.012 \\
\hline \multicolumn{4}{|l|}{ Aortic stiffness } \\
\hline Aortic pulse wave velocity, m/s & $0.2(-0.8,1.2)$ & $0.6(-0.2,1.4)$ & 0.761 \\
\hline \multicolumn{4}{|l|}{ LV structure } \\
\hline End-diastolic volume, $\mathrm{mL}$ & $-20(-34,-7)$ & $11(0,22)$ & 0.001 \\
\hline Mass, g & $-1(-11,8)$ & $22(15,30)$ & 0.005 \\
\hline Concentricity, g/mL & $0.10(0.04,0.15)$ & $0.14(0.07,0.21)$ & 0.574 \\
\hline \multicolumn{4}{|l|}{ Myocardial tissue characteristics } \\
\hline Myocardial Tg content, \% & $0.59(0.35,0.84)$ & $0.10(-0.20,0.41)$ & 0.002 \\
\hline Native T1, ms & $-25(-47,-3)$ & $-6(-31,18)$ & 0.078 \\
\hline Extracellular volume fraction, $\%$ & $1.0(-0.3,2.2)$ & $-1.9(-3.4,-0.4)$ & 0.114 \\
\hline Extracellular volume, mL & $-1(-2,4)$ & $4(2,7)$ & 0.071 \\
\hline Cell volume, $\mathrm{mL}$ & $-3(-10,4)$ & $17(12,23)$ & 0.003 \\
\hline
\end{tabular}

Adjusted for age, sex, ethnicity, smoking status (currently vs. never or previously), systolic and diastolic blood pressure. $P$ value for the interaction by ethnicity in the association between diabetes status and each cardiovascular parameter. For details on missing values see Table 2 and 3 . For abbreviations see Table 2

our results suggest that the extracellular volume fraction may not be necessarily increased in patients with longstanding T2D with concomitant antihypertensive medication use.

\section{Limitations}

Due to the cross-sectional design of our study, we cannot address issues of causality in the association of T2D with cardiovascular parameters. Our work should be considered a hypothesis-generating study and larger prospective studies are required to confirm the differential impact of T2D on LV structure and myocardial tissue characteristics between Europeans and South Asians. Due to the relatively low sample size, we could not perform subgroup analyses, for example by sex. It has been recognized that $\mathrm{T} 2 \mathrm{D}$ in women may be more detrimental for cardiac function as compared with men [53]. The South Asian as compared with the European study population was younger and, importantly, consisted of more women. Possibly, this may have introduced bias. Furthermore, there is a well-established relation between insulin resistance and high blood pressure [54, 55], which impedes the recruitment of T2D patients without hypertension. In this regard, to assess the relation of T2D to cardiovascular remodeling separately from hypertension, we adjusted for systolic and diastolic blood pressure; nonetheless, we cannot exclude residual confounding. Ideally, diabetic cardiomyopathy is studied in the absolute absence of coronary artery disease. However, a cardiac stress test was not part of our screening procedure. Furthermore, findings of previous studies indicate that several coexisting factors affect myocardial remodeling in individuals with T2D. For example, it has been demonstrated that cardiac dysfunction is worse in obese T2D patients than in individuals with T2D but without overweight [56]. Also, nutrition may interfere with the process of myocardial inflammation and fibrosis in T2D [57]. Therefore, differences in body weight and potential differences in diet between the T2D patients and controls may have partly confounded the observed relation of T2D to myocardial remodeling. 


\section{Conclusions}

LV diastolic dysfunction was identified as a common characteristic of diabetic cardiomyopathy among South Asians and Europeans. Importantly, increased LV mass was solely observed among South Asian T2D patients, whereas differences in myocardial triglyceride content between T2D patients and controls were only present in the European cohort. This study comprised detailed phenotyping of cardiovascular remodeling in T2D patients, in both South Asians and Europeans. Our results suggest that the diabetic cardiomyopathy phenotype may differ between subsets of T2D patients, for example across ethnicities. Therefore, further research on tailored strategies for T2D management may be warranted.

\begin{abstract}
Abbreviations
ACE: angiotensin-converting enzyme; BMl: body mass index; BSA: body surface area; CMR: cardiovascular magnetic resonance; E/A: ratio of transmitral early and late peak filling rate; Ea: early peak diastolic mitral septal tissue velocity; E dec peak: peak deceleration slope of the transmitral early peak filling rate; ECG: electrocardiography; ECV: extracellular volume; eGFR: estimated glomerular filtration rate; FA: flip angle; FOV: field of view; GCS: global circumferential strain; GCSR-E: global circumferential early peak diastolic strain rate; GLS: global longitudinal strain; GLSR-E: global longitudinal early peak diastolic strain rate; ${ }^{1} \mathrm{H}$-MRS: proton-magnetic resonance spectroscopy; $\mathrm{HDL}$ and LDL: high-density and low-density lipoprotein; LV: left ventricle/ventricular; MOLLI: modified Look-Locker inversion recovery; MTGC: myocardial triglyceride content; SAT: subcutaneous adipose tissue; SENSE: sensitivity encoding; T2D: type 2 diabetes; TE: echo time; Tg: triglyceride; TR: repetition time; VAT: visceral adipose tissue; venc: velocity encoding.
\end{abstract}

\section{Acknowledgements}

We are grateful to all individuals who participated in the study. We thank all physicians and nurses from Leiden University Medical Center (Leiden, The Netherlands) and Haaglanden Medical Center (The Hague, The Netherlands) for inviting eligible patients, P.J. van den Boogaard for the support in the CMR acquisition and B. Ladan-Eygenraam for the assistance in the clinical data collection.

\section{Authors' contributions}

EHMP drafted the manuscript. EHMP, HJvE and HJL designed the study. PdH and $\mathrm{HJL}$ developed the scanning protocol. EHMP, HJVE and MBB were responsible for patient and volunteer recruitment and acquired the data. HJL, IMJ and JWAS supervised the study. EHMP, HJVE, IAD and HJL were involved in the data analysis. All authors critically reviewed the manuscript. All authors read and approved the final manuscript.

\section{Funding}

This work was supported by the 'Cardio Vascular Imaging Group (CVIG)', Leiden University Medical Center (Leiden, The Netherlands), Roba Metals B.V. IJsselstein (Utrecht, The Netherlands) and Novo Nordisk A/S (Bagsvaerd, Denmark). Novo Nordisk had no role in the study design, data collection and analysis or reporting of results.

\section{Availability of data and materials}

The datasets generated during and/or analyzed during the current study are available from the corresponding author on reasonable request.

\section{Ethics approval and consent to participate}

The study was approved by the local institutional review board (Leiden University Medical Center, Leiden, The Netherlands) and complies with the revised Declaration of Helsinki. All participants provided written informed consent prior to enrolment into the study.

\section{Consent for publication}

Not applicable.

\section{Competing interests}

The authors declare that they have no competing interests.

\section{Author details}

${ }^{1}$ Dept. Radiology, Leiden University Medical Center, P.O. Box 9600, Postal Zone C2-S, 2300 RC Leiden, The Netherlands. ${ }^{2}$ Dept. Internal Medicine, Leiden University Medical Center, P.O. Box 9600, Postal Zone C7-Q, 2300 RC Leiden, The Netherlands. ${ }^{3}$ Dept. Internal Medicine, Radboud University Medical Center, P.O. Box 9101, 6500 HB Nijmegen, The Netherlands.

Received: 22 August 2019 Accepted: 1 October 2019

Published online: 11 October 2019

\section{References}

1. Marwick TH, Ritchie R, Shaw JE, Kaye D. Implications of underlying mechanisms for the recognition and management of diabetic cardiomyopathy. J Am Coll Cardiol. 2018:71(3):339-51.

2. Tillin T, Hughes AD, Mayet J, Whincup P, Sattar N, Forouhi NG, et al. The relationship between metabolic risk factors and incident cardiovascular disease in Europeans, South Asians, and African Caribbeans: SABRE (Southall and Brent Revisited) — a prospective population-based study. J Am Coll Cardiol. 2013;61(17):1777-86.

3. Kanaya AM, Wassel CL, Mathur D, Stewart A, Herrington D, Budoff MJ, et al. Prevalence and correlates of diabetes in South Asian Indians in the United States: findings from the metabolic syndrome and atherosclerosis in South Asians living in America study and the multi-ethnic study of atherosclerosis. Metab Syndr Relat Disord. 2010;8(2):157-64.

4. Shah AD, Kandula NR, Lin F, Allison MA, Carr J, Herrington D, et al. Less favorable body composition and adipokines in South Asians compared with other US ethnic groups: results from the MASALA and MESA studies. Int J Obes. 2016;40(4):639-45.

5. Gujral UP, Vittinghoff E, Mongraw-Chaffin M, Vaidya D, Kandula NR, Allison $M$, et al. Cardiometabolic abnormalities among normal-weight persons from five racial/ethnic groups in the United States: a cross-sectional analysis of two cohort studies. Ann Intern Med. 2017;166(9):628-36.

6. Nightingale CM, Rudnicka AR, Owen CG, Wells JC, Sattar N, Cook DG, et al. Influence of adiposity on insulin resistance and glycemia markers among U.K, Children of South Asian, black African-Caribbean, and white European origin: child heart and health study in England. Diabetes Care. 2013;36(6):1712-9.

7. Flowers E, Lin F, Kandula NR, Allison M, Carr JJ, Ding J, et al. Body composition and diabetes risk in South Asians: findings from the MASALA and MESA studies. Diabetes Care. 2019;42(5):946-53.

8. Abate N, Chandalia M, Snell PG, Grundy SM. Adipose tissue metabolites and insulin resistance in nondiabetic Asian Indian men. J Clin Endocrinol Metab. 2004:89(6):2750-5.

9. Forouhi NG, Sattar N, McKeigue PM. Relation of C-reactive protein to body fat distribution and features of the metabolic syndrome in Europeans and South Asians. Int J Obes Relat Metab Disord. 2001;25(9):1327-31.

10. Park CM, Tillin T, March K, Ghosh AK, Jones S, Wright A, et al. Hyperglycemia has a greater impact on left ventricle function in South Asians than in Europeans. Diabetes Care. 2014;37(4):1124-31.

11. Rijzewijk LJ, van der Meer RW, Lamb HJ, de Jong HW, Lubberink M, Romijn JA, et al. Altered myocardial substrate metabolism and decreased diastolic function in nonischemic human diabetic cardiomyopathy: studies with cardiac positron emission tomography and magnetic resonance imaging. J Am Coll Cardiol. 2009;54(16):1524-32.

12. Levelt E, Mahmod M, Piechnik SK, Ariga R, Francis JM, Rodgers CT, et al. Relationship between left ventricular structural and metabolic remodeling in type 2 diabetes. Diabetes. 2016;65(1):44-52.

13. Rijzewijk LJ, van der Meer RW, Smit JW, Diamant M, Bax JJ, Hammer $\mathrm{S}$, et al. Myocardial steatosis is an independent predictor of diastolic dysfunction in type 2 diabetes mellitus. J Am Coll Cardiol. 2008;52(22):1793-9.

14. Ng AC, Delgado V, Bertini M, van der Meer RW, Rijzewijk LJ, Hooi Ewe $S$, et al. Myocardial steatosis and biventricular strain and strain 
rate imaging in patients with type 2 diabetes mellitus. Circulation. 2010;122(24):2538-44.

15. Schuster A, Hor KN, Kowallick JT, Beerbaum P, Kutty S. Cardiovascular magnetic resonance myocardial feature tracking: concepts and clinical applications. Circ Cardiovasc Imaging. 2016;9(4)::004077.

16. Shah RV, Abbasi SA, Neilan TG, Hulten E, Coelho-Filho O, Hoppin A, et al. Myocardial tissue remodeling in adolescent obesity. J Am Heart Assoc. 2013;2(4):e000279.

17. Bizino MB, Jazet IM, Westenberg JJM, van Eyk HJ, Paiman EHM, Smit JWA, et al. Effect of liraglutide on cardiac function in patients with type 2 diabetes mellitus: randomized placebo-controlled trial. Cardiovasc Diabetol. 2019;18(1):55

18. van Eyk HJ, Paiman EHM, Bizino MB, de Heer P, Geelhoed-Duijvestijn PH, Kharagjitsingh AV, et al. A double-blind, placebo-controlled, randomised trial to assess the effect of liraglutide on ectopic fat accumulation in South Asian type 2 diabetes patients. Cardiovasc Diabetol. 2019;18(1):87.

19. Paelinck BP, de Roos A, Bax JJ, Bosmans JM, van Der Geest RJ, Dhondt D, et al. Feasibility of tissue magnetic resonance imaging: a pilot study in comparison with tissue Doppler imaging and invasive measurement. J Am Coll Cardiol. 2005:45(7):1109-16.

20. Westenberg JJ, Roes SD, Ajmone Marsan N, Binnendijk NM, Doornbos J, Bax JJ, et al. Mitral valve and tricuspid valve blood flow: accurate quantification with $3 \mathrm{D}$ velocity-encoded MR imaging with retrospective valve tracking. Radiology. 2008;249(3):792-800.

21. Brandts A, Bertini M, van Dijk EJ, Delgado V, Marsan NA, van der Geest RJ, et al. Left ventricular diastolic function assessment from three-dimensional three-directional velocity-encoded MRI with retrospective valve tracking. J Magn Reson Imaging. 2011;33(2):312-9.

22. Grotenhuis HB, Westenberg JJ, Steendijk P, van der Geest RJ, Ottenkamp J, Bax JJ, et al. Validation and reproducibility of aortic pulse wave velocity as assessed with velocity-encoded MRI. J Magn Reson Imaging. 2009;30(3):521-6.

23. de Heer P, Bizino MB, Versluis MJ, Webb AG, Lamb HJP. Improved cardiac proton magnetic resonance spectroscopy at $3 \mathrm{~T}$ using high permittivity pads. Investig Radiol. 2016;51(2):134-8.

24. Rial B, Robson MD, Neubauer S, Schneider JE. Rapid quantification of myocardial lipid content in humans using single breath-hold $1 \mathrm{H}$ MRS at 3 Tesla. Magn Reson Med. 2011;66(3):619-24.

25. Naressi A, Couturier C, Devos JM, Janssen M, Mangeat C, de Beer R, et al. Java-based graphical user interface for the MRUI quantitation package. MAGMA. 2001;12(2-3):141-52.

26. Naressi A, Couturier C, Castang I, de Beer R, Graveron-Demilly D. Javabased graphical user interface for MRUI, a software package for quantitation of in vivo/medical magnetic resonance spectroscopy signals. Comput Biol Med. 2001;31(4):269-86.

27. Diamant M, Lamb HJ, Groeneveld Y, Endert EL, Smit JW, Bax JJ, et al. Diastolic dysfunction is associated with altered myocardial metabolism in asymptomatic normotensive patients with well-controlled type 2 diabetes mellitus. J Am Coll Cardiol. 2003;42(2):328-35.

28. Paulus WJ, Tschope C. A novel paradigm for heart failure with preserved ejection fraction: comorbidities drive myocardial dysfunction and remodeling through coronary microvascular endothelial inflammation. J Am Coll Cardiol. 2013;62(4):263-71.

29. Rider OJ, Francis JM, Ali MK, Holloway C, Pegg T, Robson MD, et al. Effects of catecholamine stress on diastolic function and myocardial energetics in obesity. Circulation. 2012;125(12):1511-9.

30. Gulsin GS, Swarbrick DJ, Hunt WH, Levelt E, Graham-Brown MPM, Parke $\mathrm{KS}$, et al. Relation of aortic stiffness to left ventricular remodeling in younger adults with type 2 diabetes. Diabetes. 2018;67(7):1395-400

31. van der Meer RW, Diamant M, Westenberg JJ, Doornbos J, Bax JJ, de Roos A, et al. Magnetic resonance assessment of aortic pulse wave velocity, aortic distensibility, and cardiac function in uncomplicated type 2 diabetes mellitus. J Cardiovasc Magn Reson. 2007;9(4):645-51.

32. Boyer JK, Thanigaraj S, Schechtman KB, Perez JE. Prevalence of ventricular diastolic dysfunction in asymptomatic, normotensive patients with diabetes mellitus. Am J Cardiol. 2004;93(7):870-5.

33. Ng AC, Delgado V, Bertini M, van der Meer RW, Rijzewijk $L$, Shanks M, et al. Findings from left ventricular strain and strain rate imaging in asymptomatic patients with type 2 diabetes mellitus. Am J Cardiol. 2009;104(10):1398-401.
34. Fang ZY, Yuda S, Anderson V, Short L, Case C, Marwick TH. Echocardiographic detection of early diabetic myocardial disease. J Am Coll Cardiol. 2003;41(4):611-7.

35. Ernande L, Bergerot C, Girerd N, Thibault H, Davidsen ES, Gautier PignonBlanc $P$, et al. Longitudinal myocardial strain alteration is associated with left ventricular remodeling in asymptomatic patients with type 2 diabetes mellitus. J Am Soc Echocardiogr. 2014;27(5):479-88.

36. Ernande L, Bergerot C, Rietzschel ER, De Buyzere ML, Thibault H, Pignonblanc PG, et al. Diastolic dysfunction in patients with type 2 diabetes mellitus: is it really the first marker of diabetic cardiomyopathy? J Am Soc Echocardiogr. 2011;24(11):1268-1275.e1.

37. Zile MR, Baicu CF, Gaasch WH. Diastolic heart failure-abnormalities in active relaxation and passive stiffness of the left ventricle. N Engl I Med. 2004:350(19):1953-9.

38. Bertoni AG, Goff DC Jr, D'Agostino RB Jr, Liu K, Hundley WG, Lima JA, et al. Diabetic cardiomyopathy and subclinical cardiovascular disease: the multi-ethnic study of atherosclerosis (MESA). Diabetes Care. 2006;29(3):588-94

39. Masuo K, Rakugi H, Ogihara T, Esler MD, Lambert GW. Cardiovascular and renal complications of type 2 diabetes in obesity: role of sympathetic nerve activity and insulin resistance. Curr Diabetes Rev. 2010;6(2):58-67.

40. Tillin T, Sattar N, Godsland IF, Hughes AD, Chaturvedi N, Forouhi NG. Ethnicity-specific obesity cut-points in the development of type 2 diabetes - a prospective study including three ethnic groups in the United Kingdom. Diabet Med. 2015;32(2):226-34.

41. Shah AS, Khoury PR, Dolan LM, Ippisch HM, Urbina EM, Daniels SR, et al. The effects of obesity and type 2 diabetes mellitus on cardiac structure and function in adolescents and young adults. Diabetologia. 2011;54(4):722-30.

42. Levelt E, Pavlides M, Banerjee R, Mahmod M, Kelly C, Sellwood J, et al. Ectopic and visceral fat deposition in lean and obese patients with type 2 diabetes. J Am Coll Cardiol. 2016;68(1):53-63.

43. McGavock JM, Lingvay I, Zib I, Tillery T, Salas N, Unger R, et al. Cardiac steatosis in diabetes mellitus: a $1 \mathrm{H}$-magnetic resonance spectroscopy study. Circulation. 2007:116(10):1170-5.

44. Christoffersen C, Bollano E, Lindegaard ML, Bartels ED, Goetze JP, Andersen $\mathrm{CB}$, et al. Cardiac lipid accumulation associated with diastolic dysfunction in obese mice. Endocrinology. 2003;144(8):3483-90.

45. Atkinson LL, Kozak R, Kelly SE, Onay Besikci A, Russell JC, Lopaschuk GD. Potential mechanisms and consequences of cardiac triacylglycerol accumulation in insulin-resistant rats. Am J Physiol Endocrinol Metab. 2003;284(5):E923-30.

46. Zhou YT, Grayburn P, Karim A, Shimabukuro M, Higa M, Baetens D, et al. Lipotoxic heart disease in obese rats: implications for human obesity. Proc Natl Acad Sci USA. 2000;97(4):1784-9.

47. van Schinkel $L D$, Bakker $L E$, Jonker JT, de Roos $A$, Pijl $H$, Meinders $A E$, et al. Functional and metabolic imaging of the cardiovascular system in young healthy South Asians and Caucasians unveils early differences. Diabetes Care. 2013;36(10):e178-9.

48. Van Schinkel LD, Bakker LE, Jonker JT, De Roos A, Pijl H, Meinders AE, et al. Cardiovascular flexibility in middle-aged overweight South Asians vs white Caucasians: response to short-term caloric restriction. Nutr Metab Cardiovasc Dis. 2015;25(4):403-10.

49. van der Meer RW, Rijzewijk LJ, Diamant M, Hammer S, Schar M, Bax JJ, et al. The ageing male heart: myocardial triglyceride content as independent predictor of diastolic function. Eur Heart J. 2008;29(12):1516-22.

50. Lamb HJ, Smit JW, van der Meer RW, Hammer S, Doornbos J, de Roos A, et al. Metabolic MRI of myocardial and hepatic triglyceride content in response to nutritional interventions. Curr Opin Clin Nutr Metab Care. 2008;11(5):573-9.

51. Storz C, Hetterich H, Lorbeer R, Heber SD, Schafnitzel A, Patscheider $H$, et al. Myocardial tissue characterization by contrast-enhanced cardiac magnetic resonance imaging in subjects with prediabetes, diabetes, and normal controls with preserved ejection fraction from the general population. Eur Heart J Cardiovasc Imaging. 2018;19(6):701-8.

52. Cao Y, Zeng W, Cui Y, Kong X, Wang M, Yu J, et al. Increased myocardial extracellular volume assessed by cardiovascular magnetic resonance $\mathrm{T1}$ mapping and its determinants in type 2 diabetes mellitus patients with normal myocardial systolic strain. Cardiovasc Diabetol. 2018;17(1):7.

53. Kannel WB, McGee DL. Diabetes and cardiovascular disease. The Framingham study. JAMA. 1979;241(19):2035-8. 
54. Ferrannini E, Buzzigoli G, Bonadonna R, Giorico MA, Oleggini M, Graziadei $\mathrm{L}$, et al. Insulin resistance in essential hypertension. N Engl J Med. 1987;317(6):350-7.

55. Eckel RH, Grundy SM, Zimmet PZ. The metabolic syndrome. Lancet. 2005;365(9468):1415-28.

56. Suto M, Tanaka H, Mochizuki Y, Mukai J, Takada H, Soga F, et al. Impact of overweight on left ventricular function in type 2 diabetes mellitus. Cardiovasc Diabetol. 2017;16(1):145.

57. Waldman M, Cohen K, Yadin D, Nudelman V, Gorfil D, Laniado-Schwartzman M, et al. Regulation of diabetic cardiomyopathy by caloric restriction is mediated by intracellular signaling pathways involving 'SIRT1 and PGC1alpha'. Cardiovasc Diabetol. 2018;17(1):111.

\section{Publisher's Note}

Springer Nature remains neutral with regard to jurisdictional claims in published maps and institutional affiliations.
Ready to submit your research? Choose BMC and benefit from:

- fast, convenient online submission

- thorough peer review by experienced researchers in your field

- rapid publication on acceptance

- support for research data, including large and complex data types

- gold Open Access which fosters wider collaboration and increased citations

- maximum visibility for your research: over 100M website views per year

At BMC, research is always in progress.

Learn more biomedcentral.com/submissions 